\title{
Phytopathology
}

\section{Tale of the Huanglongbing Disease Pyramid in the Context of the Citrus Microbiome}

\author{
Nian Wang, Lukasz L. Stelinski, Kirsten S. Pelz-Stelinski, James H. Graham, and Yunzeng Zhang
}

First and fifth authors: Department of Microbiology and Cell Science, second and third authors: Department of Entomology and Nematology, and fourth author: Department of Soil and Water Sciences, Citrus Research and Education Center, Institute of Food and Agricultural Sciences,

University of Florida, Lake Alfred, FL.

Accepted for publication 7 January 2017.

\begin{abstract}
The Huanglongbing (HLB) disease pyramid is composed of Liberibacters, psyllid vectors, citrus hosts, and the environment. The epidemiological outcomes for Liberibacter-associated plant diseases are collectively determined by the inherent relationships among plant-Liberibacters-psyllids, and how various environmental factors affect plant-Liberibacter-psyllid interactions. Citrus-Liberibacter-psyllid interactions occur in a complex microbiome system. In this review, we focus on the progress in understanding the HLB disease pyramid, and how the microbiome affects the HLB disease pyramid including the interaction between HLB and the citrus microbiome; the interaction between Liberibacters and psyllids; the interaction between Liberibacters and gut microbiota in psyllids; and the effect of HLB on selected above- and belowground citrus pathogens. Their implications for HLB management are also discussed.
\end{abstract}

Additional keywords: Asian citrus psyllid, 'Candidatus Liberibacter asiaticus', citrus greening.

Citrus Huanglongbing (HLB, citrus greening) is a devastating bacterial disease affecting citrus production worldwide. The HLB disease pyramid is composed of Liberibacters, psyllid vectors, citrus hosts, and the environment. The HLB-associated Liberibacters are phloem-limited fastidious $\alpha$-Proteobacteria and consist of 'Candidatus Liberibacter asiaticus' (Las), ' $\mathrm{Ca}$. L. africanus' (Laf), and ' $C a$. L. americanus' (Lam) (Teixeira et al. 2005; Garnier et al. 2000; Jagoueix et al. 1994). Las, Laf, and Lam live either inside the phloem of plant hosts or inside citrus psyllids such as Asian citrus psyllid (Diaphorina citri) and African citrus psyllid (Trioza erytreae) (Bové 2006) and cannot live freely outside of their hosts. The epidemiological outcomes for Liberibacter-associated plant diseases are collectively determined by the inherent relationships between plant Liberibacters and psyllids, and how various environmental factors affect citrus-Liberibacter-psyllid interactions. Citrus-Liberibacter-psyllid interactions occur in a complex microbiome system (Fig. 1). Here, we review the progress in understanding the interactions among the different components of the HLB disease pyramid and how the microbiome affects the HLB disease pyramid. We intend to circumvent the areas related to the

Corresponding authors: N. Wang, L. L. Stelinski, K. S. Pelz-Stelinski, and J. H. Graham; E-mail addresses: nianwang@ufl.edu, pelzstelinski@ufl.edu, stelinski@ufl.edu, and jhgraham@ufl.edu

(c) 2017 The American Phytopathological Society
HLB disease pyramid that have been reviewed extensively, e.g., Las and plant interactions, as presented in several recent reviews (Bové 2006; da Graça et al. 2016; Gottwald 2010; Grafton-Cardwell et al. 2013; Wang and Trivedi 2013). Instead, we intend to focus on the direct or indirect reciprocal interactions between Liberibacters and psyllids and their effects on the citrus hosts that have not been covered extensively. In addition, we will examine how HLB affects the citrus microbiome; how microbes affect HLB disease development; the interactions between Liberibacters and gut microbiota in psyllids; and the effect of HLB on selected above- and belowground citrus pathogens. Their implications for HLB management are also discussed.

\section{EFFECT OF HLB ON THE CITRUS MICROBIOME}

There are a myriad of microorganisms, which mostly include bacteria, archaea, and fungi, colonizing proximal to, on and within plant tissues. Depending on their habitats, the assembled microbial communities are called the rhizosphere microbiome, rhizoplane microbiome, endosphere microbiome and phyllosphere microbiome, respectively (Turner et al. 2013; Vandenkoornhuyse et al. 2015; Wang et al. 2015). Plants provide niches, e.g., phyllosphere and rhizosphere, for the microbiomes, and in turn, they profit from the microbiome-encoded functions, such as phytohormone production, nitrogen fixation, phosphate solubilization, and antibiotic production, resulting in improved growth, 
development, nutrient uptake, and disease resistance (Lebeis 2015; Panke-Buisse et al. 2015; Reinhold-Hurek et al. 2015; Vandenkoornhuyse et al. 2015).

Liberibacters associated with HLB are phloem-limited and do not interact with other microbes of the citrus microbiome directly unless they live inside the citrus phloem. As systemic bacterial pathogens, Liberibacters cause dramatic metabolic and regulatory changes in their citrus hosts, which indirectly affect the citrus microbiome. Particularly, transport of photoassimilates is impaired due to phloem malfunction (Wang and Trivedi 2013), which probably decreases the release of the plant-derived photosynthetic products at the beginning of the infection process. Root infection and decline have been documented for HLB-affected trees (Johnson et al. 2014), which affects the composition of carbon lost from roots (rhizodeposition including sloughed-off root cap and border cells, mucilage, and exudates). HLB also affects plant defenses (Wang and Trivedi 2013), which in turn impacts the citrus microbiome.

Rhizosphere. Gradients of carbon sources, phytochemicals, $\mathrm{pH}$, oxygen, and nutrients are imposed by the host roots in the rhizosphere, and a fraction of the microorganisms in the bulk soil is driven by these gradients (Reinhold-Hurek et al. 2015). In the citrus rhizosphere microbiome, Proteobacteria are more abundant compared with the bulk soil bacterial community, whereas Actinobacteria and Acidobacteria are decreased in relative abundance compared with bulk soil. The composition of the citrus rhizosphere microbiome is dramatically shifted by HLB toward a bulk soillike bacterial community as revealed by a $16 \mathrm{~S}$ rDNA-based analysis (Trivedi et al. 2012). Shotgun metagenomic analysis of the citrus rhizosphere microbiome indicates the taxonomic composition of the rhizosphere microbial community is not significantly altered between healthy and HLB-diseased citrus trees (Y. Zhang and $\mathrm{N}$. Wang, unpublished data). The differences in HLB impact on the citrus rhizosphere microbiome observed in these two studies might have resulted from multiple factors, including genomic background of the citrus tree selected, tree age, and development stage of Las infection. The methodology difference between the two studies also could contribute to the observed difference since the assembly-based shotgun metagenomics provides higher accuracy for taxonomic detection than 16S rDNA based analysis (Ranjan et al. 2016). When investigated at higher resolution (i.e., at the genus level), both studies consistently demonstrate an HLB-associated decrease in the relative abundance of multiple bacterial genera including Burkholderia, Rhodobacter, Sphingobium, and Sphingomonas (Trivedi et al. 2012) (Y. Zhang and N. Wang, unpublished data). Besides disruption of the bacterial community structure, QPCR and GeoChip 3.0 reveal key processes, including carbon, nitrogen, and phosphorus uptake by the citrus microbiome are reduced in the rhizosphere of HLB-diseased trees (Trivedi et al. 2012). Metagenomic and metatranscriptomic analyses further demonstrate the functional features involved in plant derived nutrient utilization (e.g., $s a c A, s a c B$, and $s a c C$ for sucrose utilization) and plant-microbe and microbe-microbe interactions (e.g., secretion systems, bacterial motility, and chemotaxis) are decreased in relative abundance and expression activity in the rhizosphere microbiome of HLB-diseased trees is decreased compared with healthy counterparts (Y. Zhang and N. Wang, unpublished data).

\section{FIGURE 1}

The Huanglongbing (HLB) disease pyramid in the context of citrus microbiome. The HLB disease pyramid is composed of Liberibacters, psyllid vectors, plant hosts (i.e., citrus), and the environment. The HLB causing Liberibacters, e.g., 'Candidatus Liberibacter asiaticus' (Las) (Courtesy

of S. Y. Folimonova and D. Achor, Citrus Research and Education Center [CREC], University of Florida [UF]), are phloem-limited and systemically distributed in planta (e.g., phloems in the leaf, stem, and roots) and transmitted by Asian citrus psyllid (Diaphorina citri) and African citrus psyllid (Trioza erytreae). Las interacts with other

members of the gut microbiota (courtesy of

M. Davis, CREC, UF) of psyllids (courtesy of M. Rogers, CREC, UF). The epidemiological outcomes for Liberibacter-associated plant diseases are collectively determined by the inherent relationships between plant-Liberibacters-psyllids,

and how various environment factors affect plant-Liberibacter-psyllid interactions. The citrus-Liberibacter-psyllid interactions occur

in a complex microbiome system. The plant microbiome consists of microorganisms (e.g., bacteria and fungi) in the phyllosphere (aboveground

portions of plants): the rhizosphere (the area

surrounding the plant root), the rhizoplane (the root-soil interface), and the endosphere (internal compartments)

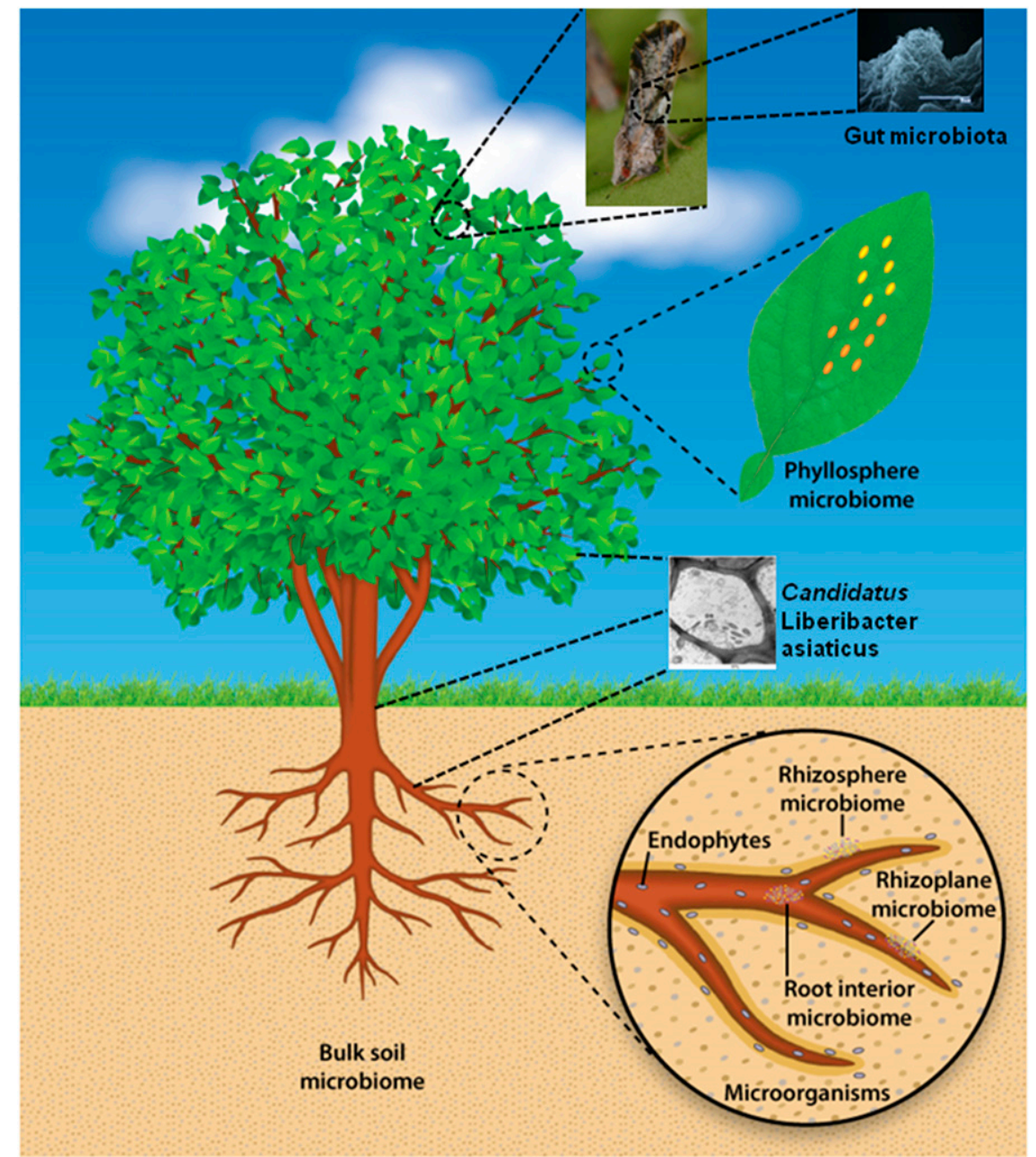


Rhizoplane. The rhizoplane is the interface linking the rhizosphere and endosphere microhabitats, and plays a critical role in controlling microbe entry into root tissues. The microbial community colonizing the rhizoplane has a more intimate relationship and is subjected to much higher selection pressures by the host root compared with the rhizosphere microbiome (Reinhold-Hurek et al. 2015). The rhizosphere to rhizoplane enrichment process probably reflects the host's preference and successful adaption of the enriched microorganisms. Zhang et al. performed a metagenomic and metatranscriptomic study to identify the citrus rhizoplane enriched taxonomic and functional properties and how HLB affected the enriched community (Y. Zhang and N. Wang, unpublished data). Compared with the citrus rhizosphere microbiome, the rhizoplane microbiome is much higher in relative abundance of beneficial taxa including Bradyrhizobium, Burkholderia, Variovorax, Caulobacter, Bdellovibrio, Chryseobacterium, and Dyadobacter. Higher relative abundance in the rhizoplane microbiome compared with the rhizosphere microbiome is also observed for multiple critical functional properties involved in host-microbe and microbe-microbe interactions, including flagella and pilus assembly, chemotaxis, and bacterial secretion systems and associated effectors. Almost all of the rhizoplane enriched genera are in relatively higher abundance in healthy compared with HLB-diseased rhizoplane samples. Most of the rhizoplane enriched functional properties involved in host-microbe and microbe-microbe interactions are significantly lower in relative abundance and expression activity in the HLB rhizoplane compared with healthy rhizoplane, indicative of impaired rhizoplane microbiome-host interactions in HLB-diseased trees.

Endosphere. Certain microorganisms of the rhizoplane microbiome enter and inhabit the endosphere (internal root tissues). The endosphere microbiome has direct contact with plant cells (ReinholdHurek et al. 2015; Santoyo et al. 2016). The host can profit from endophyte-encoded functions, particularly growth promotion and immune system modulation (Santoyo et al. 2016). Bacterial strains isolated from healthy citrus roots, including Burkholderia, Pantoea, Variovorax, Bacillus, Brevibacillus, and Paenibacillus, possess plant growth promotion traits, including phosphorus solubilization, siderophore production, nitrogen fixation, production of antibiotics, increased chitinase or salicylic acid activity, or indole acetic acid synthesis (Trivedi et al. 2011). The relative abundance of the taxa detected in healthy samples is decreased in HLB trees, while taxa rarely found in a healthy citrus endosphere microbiome, such as Methylobacterium, Sphingobacterium, and Staphylococcus, are relatively abundant in the HLB root endosphere microbiome (Trivedi et al. 2010, 2011). Importantly, beneficial traits involved in plant growth promotion and pathogen antagonism encoded by the endosphere microbiome are reduced by HLB (Trivedi et al. 2010).

Phyllosphere. The microorganisms inhabiting the phyllosphere are extremely nutrient-limited and exposed to rapid and pronounced environmental changes (Lindow and Brandl 2003). These microorganisms are from variable inoculum sources, including aerosols, insects, and soil, which make the assembled phyllosphere microbiome much more diverse than the microbiome in the rhizosphere (Bodenhausen et al. 2013; Maignien et al. 2014; Vorholt 2012). The phyllosphere microbiome plays an important role for host protection and productivity (Ritpitakphong et al. 2016; Vorholt 2012). The role of the citrus phyllosphere microbiome remains elusive. HLB affects the microbial community composition of leaf midribs even though the mechanism underlying the changes and how HLB affects the overall phyllosphere microbiome remain unknown (Sagaram et al. 2009).

\section{EFFECT OF CITRUS MICROBIOME ON HLB DEVELOPMENT}

The plant microbiome affects plant health and productivity (Berg et al. 2014; Schlaeppi and Bulgarelli 2015; Turner et al. 2013).
Many microbes are known to induce or prime plant defenses against a broad range of pathogens and insect herbivores (Maksimov et al. 2011; Pieterse et al. 2014). Additionally, the plant microbiome is a crucial player in global biogeochemical cycles, participating significantly in biochemical cycling of photoassimilates (Turner et al. 2013). Plant-associated microbes can have positive effects on plant growth. Among soil microbes, plant growth promoting bacteria are commonly associated with plants and present in most environments (Glick 2012). Soil fungi have also been reported to influence pathogen levels and play a significant role in improving plant health, e.g., Trichoderma spp. and mycorrhizal fungi (Blaya et al. 2013; Graham 2008; Graham et al. 1995). Beneficial microbes have been suggested to contribute to reducing, but not stopping, Las infection and associated symptom development of Las-infected trees by either inducing plant defense against Las or D. citri (N. Wang, unpublished data). Manipulation of root microbiomes via application of microbial products has been used to manage HLB. Preliminary results suggest that manipulation of the soil microbes has no effect on HLB disease control once the infected trees become severely symptomatic, whereas some beneficial microbes reduce, but do not prevent Las infection when applied on healthy, asymptomatic trees or symptomatic trees at the early stage of infection (N. Wang, unpublished data).

\section{LAS-D. CITRI INTERACTIONS AND ASSOCIATED IMPACT ON HLB}

D. citri, the insect vector of Las, is an essential component of the HLB disease pyramid. The interactions between Las and D. citri include both direct and indirect reciprocal interactions through their effects on the citrus hosts.

Indirect effects of Las via plant responses on host selection by $D$. citri. Insects integrate many competing infochemicals emitted by plants to locate their hosts (Dicke 2000). In search of a suitable host, insect herbivores evaluate the quality of a potential host versus surrounding competitors. D. citri females are attracted to volatiles emitted by citrus leaves damaged by conspecific psyllid feeding damage. Feeding by $D$. citri on citrus induces release of methyl salicylate (MeSA) (Mann et al. 2012). MeSA alone attracts D. citri at the specific dosage released by psyllid-damaged plants (Mann et al. 2012). The benefit of attraction to damaged plants by $D$. citri females might be related to the requirement for multiple matings to maintain optimal fertility and fecundity (Wenninger and Hall 2008). Consistently finding males for mating is necessary and female $D$. citri may take advantage of plants that emit damage-induced volatiles because it facilitates host detection (Halitschke et al. 2008) and mate finding.

Las affects $D$. citri indirectly by activation of the salicylic acid (SA) pathway that regulates systemic acquired resistance against a wide variety of invading pathogens (Thaler et al. 2010; Walling 2000). The activation of the SA pathway probably results from recognition of the pathogen associated molecular patterns, e.g., lipopolysaccharides and flagella, of Las even though the mechanistic understanding of the process remains unknown (Wang and Trivedi 2013). It is noteworthy that Las mitigates the negative effect of SA on itself (e.g., inducing plant defenses) by encoding one SA hydroxylase, which degrades SA (J. Li and N. Wang, unpublished data). Activation of SA resistance can suppress jasmonic acid (JA) signaling, compromising induced defense responses by plants to herbivore attack (Bostock 2005; Walters and Heil 2007). Induction of SA-regulated defenses by herbivorous insects can reduce JAregulated defenses thus constraining development of immature stages (Zarate et al. 2006). Reduced JA-regulated defense may benefit $D$. citri nymph development and could explain why damaged citrus releasing MeSA are more attractive to $D$. citri than to nondamaged plants (Mann et al. 2012).

Following brief feeding on Las-infected plants, D. citri disperse to uninfected plants possibly because of the lower nutritional 
quality of Las-infected plants compared with uninfected counterparts (Mann et al. 2012). It was suggested that this initial attraction to Las-infected plants followed by dispersal toward uninfected counterparts, the "deceptive host phenotype" hypothesis (Mauck et al. 2010), may help the pathogen to spread among plant hosts. Recently, this hypothesis was tested and supported (Martini et al. 2016). Biotic stressors, such as herbivore damage (Turlings and Wäckers 2004) or pathogen infection (Mann et al. 2012; Mas et al. 2014), induce both quantitative and qualitative changes in the bouquets of volatiles released by plants. These volatiles often attract natural enemies (Martini et al. 2014; Turlings and Wäckers 2004). Genetic modification of plants for the purpose of manipulating these volatiles to indirectly affect behavior of both pest and beneficial insects is gaining more attention (Kos et al. 2013). Also, lures that mimic induced volatiles can increase attraction of natural enemies to pests and can be used for pest management (Kelly et al. 2014).

Practical implications Las effects on host selection by D. citri for disease management. One important chemical communication pathway that has not been the subject of artificial manipulation is the indirect communication between plant pathogens and their vectors. Disruption of vector sensory systems with pathogen-induced volatiles may have practical application. Recently, Anfora et al. (2014) demonstrated that it is possible to disrupt host selection by Phthorimaea operculella Zeller (Lepidoptera: Gelechiidae) with host plant volatiles. A possible control strategy for management of the D. citri-HLB pathosystem is to manipulate behavior of the vector by deploying semiochemicals that mimic Las-infected citrus odors. It may also be possible to use these odors to disrupt $D$. citri host finding behavior. This could decrease the arrival of vectors to Las-infected citrus trees and possibly decrease the transmission process. Also, odors attached to monitoring traps may improve detection of $D$. citri populations (Aksenov et al. 2014; Coutinho-Abreu et al. 2014).

Direct and indirect effects of Las on movement of $D$. citri. There are both direct and indirect effects of Las on the movement behavior of $D$. citri. Las acquisition changes inclination for dispersal, flight capacity, and sexual attraction of D. citri (Martini et al. 2015). Ultimately, these effects increase the movement of D. citri that harbor the pathogen compared with uninfected counterparts, which may promote spread of Las by D. citri following pathogen acquisition.

The increase of short-distance dispersal by $D$. citri is likely to favor multiple inoculations of the same citrus host at different locations, whereas an increase in long-distance dispersal may favor the spread of the pathogen to new hosts. Las infection increases the probability of both short- and long-distance flights by $D$. citri compared with uninfected controls; however, the duration and the velocity of the recorded long flights are not affected following acquisition of the pathogen (Martini et al. 2015). Therefore, manipulation of long- and short-range dispersal of the vector by the pathogen may be limited by physiological flight capacity of $D$. citri (Martini et al. 2015).

Direct effects of Las on reproduction of $D$. citri. D. citri acquires Las primarily at the nymph stage of development (Inoue et al. 2009; Pelz-Stelinski et al. 2010). Occurrence of both transovarial (mother to offspring) (Pelz-Stelinski et al. 2010) and horizontal sexual transmission of Las (Mann et al. 2012) among D. citri suggests a close and long-developed relationship between the vector and pathogen. Furthermore, Las is persistently transmitted and capable of colonizing a majority of psyllid tissues, including the reproductive organs (Ammar et al. 2011). Finally, transmission of Las by adults occurs mainly after the pathogen is initially acquired by nymphs, rather than by adults (Ammar et al. 2015). Based on our current understanding of Las transmission, the direct impacts of Las on $D$. citri reproduction may critically impact how we manage HLB in the field.
Pelz-Stelinski and Killiny (2016) investigated how acquisition of Las may affect the fitness of $D$. citri given what appears to be a close evolutionary relationship between the vector and pathogen. Acquisition of Las reduced the lifespan of the vectors; however, fecundity of infected D. citri was greater than of uninfected counterparts (Pelz-Stelinski and Killiny 2016). This caused a higher overall finite rate of increase of $D$. citri reproductive output, and therefore fitness, among infected $D$. citri populations compared with uninfected counterparts, despite the associated negative effect on adult survival (Pelz-Stelinski and Killiny 2016). These results suggest that populations of $D$. citri likely increase more rapidly following acquisition of Las than those psyllid populations with lack of exposure to the pathogen.

Acquisition of Las does appear to cause higher mortality of adult D. citri compared with uninfected counterparts (Pelz-Stelinski and Killiny 2016). However, mortality of D. citri nymphs was not affected by acquisition of Las (Pelz-Stelinski and Killiny 2016). The negative impact on adult survival may be a direct result of the physiological costs associated with multiplication of the bacteria within D. citri (Ammar et al. 2011). Propagative pathogens can have metabolic or immune costs associated with multiplication (Fletcher et al. 1998). Therefore, a physiological trade-off between reproduction and lifespan has been postulated in the Las-D. citri pathosystem (Pelz-Stelinski and Killiny 2016).

Indirect effects of Las on reproduction of $\boldsymbol{D}$. citri. Las infection increases attractiveness of $D$. citri females to conspecific males (Martini et al. 2015). The possible impact of pathogen infection on sexual behavior of $D$. citri is less obvious regarding its possible consequences for pathogen spread. This behavioral change may result in a higher rate of pathogen transmission during copulation (Mann et al. 2011). Even if the rate of transmission of Las through mating is low (Mann et al. 2011), it is likely that the probability of sexual transmission would increase with the infection level of the conspecific partner. Therefore, sex-related transmission during mating among $D$. citri is likely to increase proportionally with the bacterial titer found within psyllids. Furthermore, females with higher titers of Las perform longer duration flights at a greater frequency than females with lower titers (Martini et al. 2015). Therefore, highly infected females appear more likely to explore new hosts. Given the greater attractiveness of these females to males, there may be a greater chance not only to infect a new host, but also to establish a new colony of $D$. citri that will become vectors of Las following acquisition from infected plants compared with uninfected counterparts (Martini et al. 2015).

Practical implications of Las effects on $D$. citri movement and reproduction for disease management. The effects of Las on movement, fertility and fecundity of $D$. citri will also influence disease epidemiology. Increased vector movement following acquisition should increase subsequent pathogen transmission. Long lifespans may impact vector capacity, by altering the lifetime transmission potential of the vector (Cook et al. 2008). Long lifespans facilitate more pathogen transmission, while shorter lifespans diminish the window during which transmission occurs. The production of more offspring in response to pathogen infection can increase fitness of $D$. citri populations, concomitantly increasing spread of Las by highly mobile vectors. Infected trees may contribute more to spread of the pathogen than by only serving as sources of inoculum for the vector. Increased fecundity of infected D. citri may contribute to increased transmission because of greater vector population size within heavily infected areas. Given that population growth of the $D$. citri vector may be higher in areas harboring widely accessible inoculum, removal of infected host plants (Bové 2006) continues to be a logical recommendation for HLB management. Further behavioral investigations in the field as well as epidemiological modeling are warranted to determine how these potential behavioral and reproductive modifications may influence the spread of HLB. Unfortunately, in Florida where nearly 
$100 \%$ of D. citri carry Las throughout the entire state (Coy and Stelinski 2015), inoculum removal is no longer a viable management option.

\section{INTERACTION BETWEEN LAS AND PSYLLID MICROBIOTA}

Las is also a component of the psyllid microbiota (Fig. 1). Its interactions with $D$. citri are influenced by other members of the psyllid microbiota. In addition, psyllid microbiota, including Wolbachia spp. Carsonella rudii and 'Candidatus Profftella armatura' (Nakabachi et al. 2013a), can potentially serve as donors for horizontal gene transfer for Las during its evolution, e.g., lysE gene in Las has been proposed to be acquired from ' $\mathrm{Ca}$. P. armatura' via horizontal gene transfer (Nakabachi et al. 2013a).

Phloem feeding insects such as psyllids rely on a diet that is largely deficient in amino acids (Sandström and Moran 1999). To counter this, D. citri and other insects have adapted through the incorporation of intracellular, symbiotic bacteria which supplement their nutritional needs in exchange for permanent residence in specialized bundles of cells called bacteriomes (Baumann et al. 1995). D. citri harbor a primary symbiont, the vertically transmitted 'Ca. Carsonella ruddii' (Nachappa et al. 2011; Thao et al. 2000), and a secondary symbiont, ' $C a$. P. armatura' (Nakabachi et al. 2013b), within these cells. Subandiyah et al. (2000) identified an additional endosymbiont, Arsenophonus spp., in Indonesian D. citri; however, this endosymbiont has not been confirmed in subsequent analyses. Sequencing analysis of Carsonella, a nonculturable alphaproteobacterium, by Nakabachi et al. (2006) demonstrated that its genome was small enough to consider the symbiont an "organelle-like" structure with genes related to amino acid biosynthesis being more prominent than those considered essential for life.

While endosymbionts are commonly found to provide metabolic influences through their associations, other roles may include effects on pathogen acquisition and/or transmission. Obligate or facultative symbionts may also assist in defense (Brownlie and Johnson 2009; Kaltenpoth 2009; Oliver et al. 2010). ' Ca. P. armatura' is a facultative symbiont whose genome encodes a polyketide toxin called diaphorin, which may have antimicrobial, antiparasitic, or antifungal properties (Nakabachi et al. 2013b).

Wolbachia, an endosymbiotic alphaproteobacterium commonly found in arthropod species, is also found in D. citri (Chu et al. 2016; Subandiyah et al. 2000). Wolbachia may influence host preferences or distort sex ratios through several processes, including malekilling, induced parthenogenesis, and cytoplasmic incompatibility (CI). CI, a phenomenon where mating between same-species individuals with different Wolbachia strains or infection status fails to produce viable offspring, is predicted in D. citri, as populations carrying different Wolbachia strains possess differential mitochondrial cytochrome oxidase gene sequences, and different haplotypes occur within geographically distinct populations (C. C. Chu and K. S. Pelz-Stelinski, unpublished data). Thus, Wolbachia strains can be used to identify genetic differences between $D$. citri from different locations (Liu et al. 2006). Because they may also alter host fitness or interfere with the transmission of insect-borne pathogens, Wolbachia are of interest as tools for $D$. citri management and are candidates for use in paratransgenic transformation of insect vectors as drivers for genes that may interfere with pathogen transmission.

Wolbachia, Profftella, and Carsonella infection densities are positively correlated with each other among natural $D$. citri populations, indicating that the growth of an individual endosymbiont is not significantly altered or inhibited by the growth of others (Chu et al. 2016; Hoffmann et al. 2014). Although the relative abundance of endosymbionts in D. citri is not consistently correlated with Las infection; Las-infected individuals tend to have lower endosymbiont densities compared with uninfected individuals (Chu et al. 2016). The genetic background of $D$. citri populations appears to be the most significant predictor of endosymbiont density.

Commensal associations with microorganisms are common among insect species. Host-associated microorganisms may mediate insectplant interactions, including settling, feeding, and oviposition (Douglas 2013). Insect bacterial microbiota may also reduce the infection level of various insect parasitic organisms, including pathogens, by elevating the basal level of immunity in the insect host. These microbial infection barriers have been shown to inhibit transmission of disease causing pathogens of Plasmodium falciparum and Dengue fever virus by their insect vectors (Hamilton and Perlman 2013). Allochthonous microorganisms identified in $D$. citri guts reflect the microbial communities of their citrus hosts. Among the citrus endophytes isolated from $D$. citri are Enterobacter cloacae, Alcaligenes xylosoxidans denitrificans, Pantoea agglomerans, Acromobacter sp., Pseudomonas spp., Bacillus spp., Enterobacter spp., Streptomyces spp., Staphlococcus sp., and Paenibacillus spp. Both Alcaligenes xylosoxidans denitrificans and Pantoea agglomerans are insect symbionts (Dillon et al. 2010; Lauzon et al. 2009), which may facilitate their development as gene drive systems for paratransgenic management of $D$. citri or Las management. Pantoea agglomerans has been used in studies to interrupt Plasmodium spp. in vector mosquitoes (Riehle et al. 2007; Wang et al. 2012) and A. xylosoxidans has been examined in the lab and in field trials to interrupt transmission of Xylella fastidiosa, the causative agent of Pierce's disease.

Culture-independent analyses of $D$. citri have also detected Ralstonia, Tremblayaceae, and Methylocystis heyeri-like bacteria (Kolora et al. 2015; Marutani-Hert et al. 2011). While the nature of the interaction between the commensal gut-associated microorganisms and Las remains unclear, it is apparent from Kolora et al. (2015) that the most diverse microbial communities occur in Las-infected D. citri compared with uninfected psyllids. This suggests that host endophytes may play an important role in the transmission of Las by priming $D$. citri for acquisition and subsequent transmission of Las.

\section{EFFECT OF HLB ON SELECTED ABOVE- AND BELOWGROUND CITRUS PATHOGENS}

HLB is a chronic, progressive decline disease caused by the systemic pathogens Las, Laf, and Lam, which takes long time to develop (Gottwald 2010). The gradual changes occurring in Liberibacterinfected trees including tree vigor decline, carbon loss, and decrease in plant defenses complicate citrus interactions with other pathogenic microbes of the citrus microbiome besides the aforementioned effects on the citrus microbiome. Here we will present how Las infection of citrus affects the interactions between citrus and other aboveand belowground citrus pathogens including Xanthomonas citri, Phytophthora, and Colletotrichum acutatum.

Las- $\boldsymbol{X}$. citri interaction. Las infection increases host susceptibility to $X$. citri. The increased susceptibility of Las-infected citrus to $X$. citri infection might result from the degradation of SA by the Las SA hydroxylase (J. Li and N. Wang, unpublished data). SA is critical for SAR to subsequent infection by the original pathogen or by a variety of other pathogens (Bowling et al. 1994; Fu and Dong 2013; Lawton et al. 1995). The fact that Las increases susceptibility to $X$. citri further complicates disease management issues in citrus producing areas. $X$. citri infects most commercially grown citrus varieties, including sweet orange, grapefruit and lemon $[C$. limon (L.) Burm. f.]. For the top three citrus producers, Brazil, China, and the United States, both HLB and citrus canker are present, which warrants an integrated pest management approach for both citrus HLB and canker diseases (J. Li and N. Wang, unpublished data).

Las-Phytophthora interaction. Root sampling of Las-infected trees in Florida orchards demonstrates that root dieback occurs before visible HLB symptoms in the canopy (Graham et al. 2013). Asymptomatic trees with detectable Las in fibrous roots already 
have massive fibrous root loss (Johnson et al. 2014). The order of magnitude of root loss due to HLB is equal to or greater than $30 \%$ in surveys of both young trees ( 3 to 4 years old) and older trees (10 to 25 years old) (Graham et al. 2013). In some locations, higher Phytophthora nicotianae per root, as well as Phytophthora populations per cubic centimeter of soil, are detected on Las (+) compared with Las (-) trees.

Studies in Taiwan (Ann et al. 2004) and Florida (Wu et al. 2015) suggest that increasing incidence of HLB in citrus orchards in the presence of Phytophthora nicotianae may have a greater impact on fibrous root health than that caused by Las pathogenicity alone. Lasinduced predisposition to Phytophthora nicotianae is apparently caused by a greater attraction of swimming zoospores to roots, acceleration of infection, and less resistance to root invasion. Ultimately, the Las-Phytophthora interaction may not promote more severe root damage than Las alone, but accelerate root turnover(Wu et al. 2015). Phytophthora propagules per soil volume and per root fluctuate in response to fibrous root density based on rhizosphere soil sampling. Survey data from Florida orchards also suggests a resistance-breaking interaction of Las with Phytophthora spp. (Graham et al. 2015b). Because statewide survey of Phytophthora spp. spans over 2 decades and covers all production areas, the results serve as an indicator of emerging root disease trends. Comparison of the survey data between seasons since HLB became widespread in Florida orchards shows a strong trend toward higher incidence of damaging Phytophthora populations coincident with the rise in HLB incidence. More recently there has been a strong downturn in Phytophthora spp. populations apparently associated with a loss of fibrous root density as trees continue to decline from HLB.

A series of greenhouse studies with potted seedlings investigated the interaction between Las and Phytophthora nicotianae (Wu et al. 2015). The results demonstrate the following: (i) Las infection of citrus rootstocks predisposes fibrous roots to Phytophthora nicotianae infection by increasing root leakage of exudates that attract zoospores and by disrupting host resistance (i.e., carbohydrate-mediated defense); (ii) the combination of Las and Phytophthora nicotianae does not cause greater damage than each pathogen alone; (iii) the interaction between Phytophthora nicotianae and Las on fibrous root damage is mediated by available young fibrous root biomass. More in-depth examination of the interaction between Las and Phytophthora nicotianae, reveals different disease causation mechanisms for each root pathogen. Las damages fibrous roots by inducing faster growth of replacement roots and root turnover (Johnson et al. 2015); Phytophthora nicotianae damages fibrous roots by causing rapid root collapse immediately after infection; canopy development is reduced after root damage by both pathogens. To explore disease development from the perspective of root carbohydrate metabolism responses to Las and Phytophthora nicotianae infection, sucrose metabolism related gene expression is under investigation in two rootstocks, Cleopatra mandarin (Citrus reticulata), susceptible to Phytophthora nicotianae, and Swingle citrumelo (Poncirus trifoliata $\times$ C. paradisi), tolerant to Phytophthora nicotianae. The results show that sucrose metabolism is more disrupted by Las and Phytophthora nicotianae for Phytophthora susceptible Cleopatra mandarin than for Swingle citrumelo.

The most important root stress identified in Florida orchards is bicarbonates in irrigation water and over liming of soil with dolomite which directly reduce the ability of trifoliate hybrid rootstocks, Swingle citrumelo and Carrizo citrange (Poncirus trifoliata $\times C$. sinensis), to take up important nutrients $(\mathrm{Ca}, \mathrm{Mg}, \mathrm{Zn}$, $\mathrm{Mn}$, and $\mathrm{Fe}$ ). Bicarbonates and associated elevated $\mathrm{pH}$ have also been identified as a major factor predisposing roots to infection and damage by Las and Phytophthora spp. (Graham et al. 2015a). Past research experiences and current Phytophthora data trends indicate a need for more comprehensive management of HLB-affected trees.
Fibrous root health is fundamental to sustain soil, water, and nutrient uptake; tolerance of marginal soils; fluctuations in soil moisture; root pests; and other adverse conditions. Symptoms of stress intolerance are off-colored foliage and excessive leaf and fruit drop of HLB-affected trees, even when trees have been managed under intensive nutritional programs for several seasons. Fungicide control of Phytophthora nicotianae slows infection of the root system. However, preliminary data indicate that fungicides are reduced in their effectiveness for control of Phytophthora spp. and prevention of root loss because Las infection is the major contributor to damage of co-infected roots (Johnson et al. 2015).

Las-postboom fruit drop interaction. Postbloom fruit drop, caused by the fungus Colletotrichum acutatum, affects all species and cultivars of citrus, but severity on a given cultivar varies according to the time of bloom in relation to rainfall (Peres et al. 2016). Between flowering periods, the inoculum survives as dormant infections on persistent calyces, leaves, and twigs. When flowers first open, fungal appressoria germinate and form a small number of conidiospores. Conidia are rain splash dispersed to the open flowers where they are able to germinate, infect, and produce many more spores. The new spores are then dispersed to the next open flowers by subsequent rainfall events. Infection occurs within $24 \mathrm{~h}$ of a weather event and symptoms appear in 4 to 5 days. At the end of bloom, the fungus causes the young fruitlets to abscise, leaving the persistent calyces.

In the last three seasons, postbloom fruit drop has caused widespread losses in Florida orchards. Multiple factors have contributed to the outbreaks, but the most likely factors are the extended bloom caused by HLB and warm winters. Extended bloom allows for inoculum to build up prior to the major bloom. While windblown rain is the main means of inoculum spread, orchards and cultivars with extended blooms, multiple blooms, or off-season blooms tend to have more problems than where the bloom period is restricted. Considering the potential for HLB trees to have extended bloom periods and rain during flowering, timing of fungicide sprays is more complicated than in the past. Sprays should be targeted to the major bloom and timing of applications determined by the use of the postbloom fruit drop-fungicide application decision (PFDFAD) system (http://pfd.ifas.ufl.edu).

\section{CONCLUDING REMARKS}

HLB associating Liberibacters are weak pathogens that could not live freely outside of their hosts and rely on their psyllid vectors for transformation. However, their association with psyllid vectors makes them formidable foes for the commercial citrus industry. In addition, plant-Liberibacter-psyllid interactions occur in the context of the citrus microbiome and their outcome is affected by other components of the microbiome. Successful management of HLB requires a thorough understanding of the interactions of each of the components of the HLB disease pyramid, their reciprocal interactions, and their reciprocal interactions with other components of the microbiome.

\section{LITERATURE CITED}

Aksenov, A., Martini, X., Zhao, W., Stelinski, L. L., and Davis, C. E. 2014. Synthetic blends of volatile, phytopathogen-induced odorants can be used to manipulate vector behavior. Front. Ecol. Evol. 2:1-9.

Ammar, E., Shatters, R. G., Lynch, C., and Hall, D. 2015. Replication of Candidatus Liberibacter asiaticus in its psyllid vector Diaphorina citri following various acquisition access periods. International Research Conference on Huanglongbing IV, Orlando, FL.

Ammar, E.-D., Shatters, R. G., Lynch, C., and Hall, D. G. 2011. Detection and relative titer of Candidatus Liberibacter asiaticus in the salivary glands and alimentary canal of Diaphorina citri (Hemiptera: Psyllidae) vector of citrus huanglongbing disease. Ann. Entomol. Soc. Am. 104:526-533.

Anfora, G., Vitagliano, S., Larsson, M. C., Witzgall, P., Tasin, M., Germinara, G. S., and De Cristofaro, A. 2014. Disruption of Phthorimaea operculella 
(Lepidoptera: Gelechiidae) oviposition by the application of host plant volatiles. Pest Manag. Sci. 70:628-635.

Ann, P. J., Ko, W. H., and Su, H. J. 2004. Interaction between Likubin bacterium and Phytophthora parasitica in citrus hosts. Eur. J. Plant Pathol. 110: 1-6.

Baumann, P., Baumann, L., Lai, C.Y., Rouhbakhsh, D., Moran, N. A., and Clark, M. A. 1995. Genetics, physiology, and evolutionary relationships of the genus Buchnera: Intracellular symbionts of aphids. Annu. Rev. Microbiol. 49:55-94.

Berg, G., Grube, M., Schloter, M., and Smalla, K. 2014. Unraveling the plant microbiome: Looking back and future perspectives. Front. Microbiol. 5: 148.

Blaya, J., López-Mondéjar, R., Lloret, E., Pascual, J. A., and Ros, M. 2013. Changes induced by Trichoderma harzianum in suppressive compost controlling Fusarium wilt. Pestic. Biochem. Physiol. 107:112-119.

Bodenhausen, N., Horton, M. W., and Bergelson, J. 2013. Bacterial communities associated with the leaves and the roots of Arabidopsis thaliana. PLoS ONE 8:e56329.

Bostock, R. M. 2005. Signal crosstalk and induced resistance: Straddling the line between cost and benefit. Annu. Rev. Phytopathol. 43:545-580.

Bové, J. M. 2006. Huanglongbing: A destructive, newly-emerging, century-old disease of citrus. J. Plant Pathol. 88:7-37.

Bowling, S. A., Guo, A., Cao, H., Gordon, A. S., Klessig, D. F., and Dong, X. 1994. A mutation in Arabidopsis that leads to constitutive expression of systemic acquired resistance. Plant Cell 6:1845-1857.

Brownlie, J. C., and Johnson, K. N. 2009. Symbiont-mediated protection in insect hosts. Trends Microbiol. 17:348-354.

Chu, C. C., Gill, T. A., Hoffmann, M., and Pelz-Stelinski, K. S. 2016. Interpopulation variability of endosymbiont densities in the Asian citrus psyllid (Diaphorina citri Kuwayama). Microbiol. Ecol. 71:999-1007.

Cook, P. E., McMeniman, C. J., and O'Neill, S. L. 2008. Modifying insect population age structure to control vector-borne disease. Adv. Exp. Med. Biol. 627:126-140.

Coutinho-Abreu, I. V., Forster, L., Guda, T., and Ray, A. 2014. Odorants for surveillance and control of the Asian citrus psyllid (Diaphorina citri). PLoS ONE 9:e109236.

Coy, M. R., and Stelinski, L. 2015. Great variability in the infection rate of "Candidatus Liberibacter asiaticus" in field populations of Diaphorina citri (Hemiptera: Liviidae) in Florida. Fla. Entomol. 98:356-357.

da Graça, J. V., Douhan, G. W., Halbert, S. E., Keremane, M. L., Lee, R. F., Vidalakis, G., and Zhao, H. 2016. Huanglongbing: An overview of a complex pathosystem ravaging the world's citrus. J. Integr. Plant Biol. 58: 373-387.

Dicke, M. 2000. Chemical ecology of host-plant selection by herbivorous arthropods: A multitrophic perspective. Biochem. Syst. Ecol. 28:601-617.

Dillon, R. J., Webster, G., Weightman, A. J., and Keith Charnley, A. 2010. Diversity of gut microbiota increases with aging and starvation in the desert locust. Antonie van Leeuwenhoek, Int. J. Genet. Mol. Microbiol. 97:69-77.

Douglas, A. E. 2013. Microbial brokers of insect-plant interactions revisited. J. Chem. Ecol. 39:952-961.

Fletcher, J., Wayadande, A., Melcher, U., and Ye, F. 1998. The phytopathogenic mollicute-insect vector interface: A closer look. Phytopathology 88: 1351-1358.

Fu, Z. Q., and Dong, X. 2013. Systemic acquired resistance: Turning local infection into global defense. Annu. Rev. Plant Biol. 64:839-863.

Garnier, M., Jagoueix-Eveillard, S., Cronje, P. R., Le Roux, H. F., and Bové, J. M. 2000. Genomic characterization of a Liberibacter present in an ornamental rutaceous tree, Calodendrum capense, in the Western Cape province of South Africa. Proposal of "Candidatus Liberibacter africanus subsp. capensis”. Int. J. Syst. Evol. Microbiol. 50:2119-2125.

Glick, B. R. 2012. Plant growth-promoting bacteria: Mechanisms and applications. Scientifica (Cairo) 2012:963401

Gottwald, T. R. 2010. Current epidemiological understanding on citrus Huanglongbing. Annu. Rev. Phytopathol. 48:119-139.

Grafton-Cardwell, E. E., Stelinski, L. L., and Stansly, P. A. 2013. Biology and management of Asian citrus psyllid, vector of the Huanglongbing pathogens. Annu. Rev. Entomol. 58:413-432.

Graham, J., Gerberich, K., Bright, D., and Johnson, E. 2015a. Excess bicarbonate in soil and irrigation water increases fibrous root loss and decline of Huanglongbing-affected citrus trees in Florida. J. Graham and L. Stelinski, eds. Abstracts from the 4th International Research Conference on Huanglongbing. J. Citrus Pathol. 2:15. http://escholarship.org/uc/item/ 9jw2w985

Graham, J., Gerberich, K., Bright, D., Wu, J., Johnson, E., and Taylor, J. 2015b. Relationship between HLB-induced fruit drop, fibrous root loss and the interaction with Phytophthora spp. J. Graham and L. Stelinski, eds. Abstracts from the 4th International Research Conference on Huanglongbing. J. Citrus Pathol. 2:20. http://escholarship.org/uc/item/9jw2w985
Graham, J. H. 2008. Scaling-up evaluation of field functioning of arbuscular mycorrhizal fungi. New Phytol. 180:1-2.

Graham, J. H., Hodge, N. C., and Morton, J. B. 1995. Fatty acid methyl ester profiles for characterization of glomalean fungi and their endomycorrhizae. Appl. Environ. Microbiol. 61:58-64.

Graham, J. H., Johnson, E. G., Gottwald, T. R., and Irey, M. S. 2013. Presymptomatic fibrous root decline in citrus trees caused by Huanglongbing and potential interaction with Phytophthora spp. Plant Dis. 97:1195-1199.

Halitschke, R., Stenberg, J. A., Kessler, D., Kessler, A., and Baldwin, I. T. 2008. Shared signals-"Alarm calls" from plants increase apparency to herbivores and their enemies in nature. Ecol. Lett. 11:24-34.

Hamilton, P. T., and Perlman, S. J. 2013. Host defense via symbiosis in Drosophila. PLoS Pathog. 9:e1003808.

Hoffmann, M., Coy, M. R., Kingdom Gibbard, H. N., and Pelz-Stelinski, K. S. 2014. Wolbachia infection density in populations of the Asian citrus psyllid (Hemiptera: Liviidae). Environ. Entomol. 43:1215-1222.

Inoue, H., Ohnishi, J., Ito, T., Tomimura, K., Miyata, S., Iwanami, T., and Ashihara, W. 2009. Enhanced proliferation and efficient transmission of Candidatus Liberibacter asiaticus by adult Diaphorina citri after acquisition feeding in the nymphal stage. Ann. Appl. Biol. 155:29-36.

Jagoueix, S., Bove, J. M., and Garnier, M. 1994. The phloem-limited bacterium of greening disease of citrus is a member of the alpha-subdivision of the Proteobacteria. Int. J. Syst. Bacteriol. 44:379-386.

Johnson, E. G., Gerberich, K. M., Wu, J., and Graham, J. H. 2015. Citrus huanglongbing stimulates root growth while causing overall root loss. J. Graham and L. Stelinski, eds. Abstracts from the 4th International Research Conference on Huanglongbing. J. Citrus Pathol. 2:20. http://escholarship. org/uc/item/9jw2w985

Johnson, E. G., Wu, J., Bright, D. B., and Graham, J. H. 2014. Association of "Candidatus Liberibacter asiaticus" root infection, but not phloem plugging with root loss on huanglongbing-affected trees prior to appearance of foliar symptoms. Plant Pathol. 63:290-298.

Kaltenpoth, M. 2009. Actinobacteria as mutualists: General healthcare for insects? Trends Microbiol. 17:529-535.

Kelly, J. L., Hagler, J. R., and Kaplan, I. 2014. Semiochemical lures reduce emigration and enhance pest control services in open-field predator augmentation. Biol. Control 71:70-77.

Kolora, L. D., Powell, C. M., Hunter, W., Bextine, B., and Lauzon, C. R. 2015. internal extracellular bacteria of Diaphorina citri Kuwayama (Hemiptera: Psyllidae), the Asian citrus psyllid. Curr. Microbiol. 70:710-715.

Kos, M., Houshyani, B., Overeem, A.-J., Bouwmeester, H. J., Weldegergis, B. T., van Loon, J. J., Dicke, M., and Vet, L. E. 2013. Genetic engineering of plant volatile terpenoids: Effects on an herbivore, a predator and a parasitoid. Pest Manag. Sci. 69:302-311.

Lauzon, C. R., Mccombs, S. D., Potter, S. E., and Peabody, A. N. C. 2009. Establishment and vertical passage of Enterobacter (Pantoea) agglomerans and Klebsiella pneumoniae through all life stages of the Mediterranean fruit fly (Diptera: Tephritidae). Ann. Entomol. Soc. Am. 102:85-95.

Lawton, K., Weymann, K., Friedrich, L., Vernooij, B., Uknes, S., and Ryals, J. 1995. Systemic acquired resistance in Arabidopsis requires salicylic acid but not ethylene. Mol. Plant-Microbe Interact. 8:863-870.

Lebeis, S. L. 2015. Greater than the sum of their parts: Characterizing plant microbiomes at the community-level. Curr. Opin. Plant Biol. 24: 82-86.

Lindow, S. E., and Brandl, M. T. 2003. Microbiology of the phyllosphere. Appl. Environ. Microbiol. 69:1875-1883.

Liu, D., Trumble, J. T., and Stouthamer, R. 2006. Genetic differentiation between eastern populations and recent introductions of potato psyllid (Bactericera cockerelli) into western North America. Entomol. Exp. Appl. 118: 177-183.

Maignien, L., DeForce, E. A., Chafee, M. E., Murat Eren, A., and Simmons, S. L. 2014. Ecological succession and stochastic variation in the assembly of Arabidopsis thaliana phyllosphere communities. mBio 5:e00682-13

Maksimov, I. V., Abizgil'dina, R. R., and Pusenkova, L. I. 2011. Plant growth promoting rhizobacteria as alternative to chemical crop protectors from pathogens. Appl. Biochem. Microbiol. 47:333-345.

Mann, R. S., Ali, J. G., Hermann, S. L., Tiwari, S., Pelz-Stelinski, K. S., Alborn, H. T., and Stelinski, L. L. 2012. Induced release of a plant-defense volatile 'deceptively' attracts insect vectors to plants infected with a bacterial pathogen. PLoS Pathog. 8:e1002610.

Mann, R. S., Pelz-Stelinski, K., Hermann, S. L., Tiwari, S., and Stelinski, L. L. 2011. Sexual transmission of a plant pathogenic bacterium, Candidatus Liberibacter asiaticus, between conspecific insect vectors during mating. PLoS ONE 6:e29197.

Martini, X., Hoffmann, M., Coy, M. R., Stelinski, L. L., and Pelz-Stelinski, K. S. 2015. Infection of an insect vector with a bacterial plant pathogen increases its propensity for dispersal. PLoS ONE 10:e0129373. 
Martini, X., Pelz-Stelinski, K. S., and Stelinski, L. L. 2014. Plant pathogeninduced volatiles attract parasitoids to increase parasitism of an insect vector. Front. Ecol. Evol. 2:1-8.

Martini, X., Willett, D. S., Kuhns, E. H., and Stelinski, L. L. 2016. Disruption of vector host preference with plant volatiles may reduce spread of insecttransmitted plant pathogens. J. Chem. Ecol. 42:357-367.

Marutani-Hert, M., Hunter, W. B., and Morgan, J. K. 2011. Associated bacteria of Asian citrus psyllid (Hemiptera: Psyllidae: Diaphorina citri). Southwest. Entomol. 36:323-330.

Mas, F., Vereijssen, J., and Suckling, D. M. 2014. Influence of the pathogen Candidatus Liberibacter Solanacearum on tomato host plant volatiles and psyllid vector settlement. J. Chem. Ecol. 40:1197-1202.

Mauck, K. E., De Moraes, C. M., and Mescher, M. C. 2010. Deceptive chemical signals induced by a plant virus attract insect vectors to inferior hosts. Proc. Natl. Acad. Sci. USA 107:3600-3605.

Nachappa, P., Levy, J., Pierson, E., and Tamborindeguy, C. 2011. Diversity of endosymbionts in the potato psyllid, Bactericera cockerelli (Hemiptera: Triozidae), vector of zebra chip disease of potato. Curr. Microbiol. 62:1510-1520.

Nakabachi, A., Nikoh, N., Oshima, K., Inoue, H., Ohkuma, M., Hongoh, Y., Miyagishima, S. Y., Hattori, M., and Fukatsu, T. 2013a. Horizontal gene acquisition of Liberibacter plant pathogens from a bacteriome-confined endosymbiont of their psyllid vector. PLoS ONE 8:e82612.

Nakabachi, A., Ueoka, R., Oshima, K., Teta, R., Mangoni, A., and Gurgui, M. 2013b. Defensive bacteriome symbiont with a drastically reduced genome. Curr. Biol. 23:1478-1484.

Nakabachi, A., Yamashita, A., Toh, H., Ishikawa, H., Dunbar, H. E., Moran, N. A., and Hattori, M. 2006. The 160-kilobase genome of the bacterial endosymbiont Carsonella. Science 314:267.

Oliver, K. M., Degnan, P. H., Burke, G. R., and Moran, N. A. 2010. Facultative symbionts in aphids and the horizontal transfer of ecologically important traits. Annu. Rev. Entomol. 55:247-266.

Panke-Buisse, K., Poole, A. C., Goodrich, J. K., Ley, R. E., and Kao-Kniffin, J. 2015. Selection on soil microbiomes reveals reproducible impacts on plant function. ISME J. 9:980-989.

Pelz-Stelinski, K.S., Brlansky, R.H., Ebert, T. A., and Rogers, M.E. 2010. Transmission parameters for Candidatus Liberibacter asiaticus by Asian citrus psyllid (Hemiptera: Psyllidae). J. Econ. Entomol. 103:1531-1541.

Pelz-Stelinski, K. S., and Killiny, N. 2016. Better together: Association with "Candidatus Liberibacter asiaticus" increases the reproductive fitness of its insect vector, Diaphorina citri (Hemiptera: Liviidae). Ann. Entomol. Soc. Am. 109:371-376.

Peres, N. A., Dewdney, M. M., and Graham, J. H. 2016. Post Bloom Fruit Drop. Pages 85-86 in: Florida Citrus Pest Management Guide, SP-43, PP-182. M. E. Rogers and M. M. Dewdney, eds. University of Florida, IFAS, Gainesville.

Pieterse, C. M. J., Zamioudis, C., Berendsen, R. L., Weller, D. M., Van Wees, S. C. M., and Bakker, P. A. H. M. 2014. Induced systemic resistance by beneficial microbes. Annu. Rev. Phytopathol. 52:347-375.

Ranjan, R., Rani, A., Metwally, A., McGee, H. S., and Perkins, D. L. 2016. Analysis of the microbiome: Advantages of whole genome shotgun versus $16 \mathrm{~S}$ amplicon sequencing. Biochem. Biophys. Res. Commun. 469:967-977.

Reinhold-Hurek, B., Bünger, W., Burbano, C. S., Sabale, M., and Hurek, T. 2015. Roots shaping their microbiome: Global hotspots for microbial activity. Annu. Rev. Phytopathol. 53:403-424.

Riehle, M. A., Moreira, C. K., Lampe, D., Lauzon, C., and Jacobs-Lorena, M. 2007. Using bacteria to express and display anti-plasmodium molecules in the mosquito midgut. Int. J. Parasitol. 37:595-603.

Ritpitakphong, U., Falquet, L., Vimoltust, A., Berger, A., Métraux, J. P., and L'Haridon, F. 2016. The microbiome of the leaf surface of Arabidopsis protects against a fungal pathogen. New Phytol. 210:1033-1043.

Sagaram, U. S., Deangelis, K. M., Trivedi, P., Andersen, G. L., Lu, S. E., and Wang, N. 2009. Bacterial diversity analysis of huanglongbing pathogeninfected citrus, using phyloChip arrays and 16S rRNA gene clone library sequencing. Appl. Environ. Microbiol. 75:1566-1574.

Sandström, J., and Moran, N. 1999. How nutritionally imbalanced is phloem sap for aphids? Pages 203-210 in: Proceedings of the 10th
International Symposium on Insect-Plant Relationships. Springer, Dordrecht, the Netherlands.

Santoyo, G., Moreno-Hagelsieb, G., del Carmen Orozco-Mosqueda, M., and Glick, B. R. 2016. Plant growth-promoting bacterial endophytes. Microbiol. Res. 183:92-99.

Schlaeppi, K., and Bulgarelli, D. 2015. The plant microbiome at work. Mol. Plant-Microbe Interact. 28:212-217.

Subandiyah, S., Nikoh, N., Tsuyumu, S., Somowiyarjo, S., and Fukatsu, T. 2000. Complex endosymbiotic microbiota of the citrus psyllid Diaphorina citri (Homoptera: Psylloidea). Zoolog. Sci. 17:983-989.

Teixeira, D., Saillard, C., Eveillard, S., Danet, J. L., da Costa, P. I., Ayres, A. J., and Bové, J. 2005. "Candidatus Liberibacter americanus", associated with citrus huanglongbing (greening disease) in São Paulo State, Brazil. Int. J. Syst. Evol. Microbiol. 55:1857-1862.

Thaler, J. S., Agrawal, A. A., and Rayko, H. 2010. Salicylate-mediated interactions between pathogens and herbivores. Ecology 91:1075-1082.

Thao, M. L., Moran, N. A., Abbot, P., Brennan, E. B., Burckhardt, D. H., and Baumann, P. 2000. Cospeciation of psyllids and their primary prokaryotic endosymbionts. Appl. Environ. Microbiol. 66:2898-2905.

Trivedi, P., Duan, Y. P., and Wang, N. A. 2010. Huanglongbing, a systemic disease, restructures the bacterial community associated with citrus roots. Appl. Environ. Microbiol. 76:3427-3436.

Trivedi, P., He, Z. L., Van Nostrand, J. D., Albrigo, G., Zhou, J. Z., and Wang, N. 2012. Huanglongbing alters the structure and functional diversity of microbial communities associated with citrus rhizosphere. ISME J. 6: 363-383.

Trivedi, P., Spann, T., and Wang, N. 2011. Isolation and characterization of beneficial bacteria associated with citrus roots in Florida. Microb. Ecol. 62: 324-336.

Turlings, T. C. J., and Wäckers, F. 2004. Recruitment of predators and parasitoids by herbivore-injured plants. Adv. Isect Chem. Ecol. 2:21-75.

Turner, T. R., James, E. K., and Poole, P. S. 2013. The plant microbiome. Genome Biol. 14:209.

Vandenkoornhuyse, P., Quaiser, A., Duhamel, M., Le Van, A., and Dufresne, A. 2015. The importance of the microbiome of the plant holobiont. New Phytol. 206:1196-1206.

Vorholt, J. A. 2012. Microbial life in the phyllosphere. Nat. Rev. Microbiol. 10:828-840.

Walling, L. L. 2000. The myriad plant responses to herbivores. J. Plant Growth Regul. 19:195-216.

Walters, D., and Heil, M. 2007. Costs and trade-offs associated with induced resistance. Physiol. Mol. Plant Pathol. 71:3-17.

Wang, N., Jin, T., Trivedi, P., Setubal, J. C., Tang, J. A., Machado, M. M., and Zhang, Y. 2015. Announcement of the International Citrus Microbiome (Phytobiome) Consortium. J. Citrus Pathol. http://escholarship.org/uc/item/ $5 \mathrm{xp} 3 \mathrm{v} 2 \mathrm{rc}$

Wang, N., and Trivedi, P. 2013. Citrus huanglongbing: A newly relevant disease presents unprecedented challenges. Phytopathology 103: 652-665.

Wang, S., Ghosh, A. K., Bongio, N., Stebbings, K. A., Lampe, D. J., and Jacobs-Lorena, M. 2012. Fighting malaria with engineered symbiotic bacteria from vector mosquitoes. Proc. Natl. Acad. Sci. USA 109:1273412739 .

Wenninger, E. J., and Hall, D. G. 2008. Importance of multiple mating to female reproductive output in Diaphorina citri. Physiol. Entomol. 33: 316-321.

Wu, J., Johnson, E., Bright, D., Gerberich, K., and Graham, J. 2015. The interaction between Phytophthora nicotianae and 'Candidatus Liberibacter asiaticus' damage to citrus fibrous roots. J. Graham and L. Stelinski, eds. Abstracts from the 4th International Research Conference on Huanglongbing. J. Citrus Pathol. 2:45. http://escholarship.org/uc/item/9jw2w985

Zarate, S. I., Kempema, L. A., and Walling, L. L. 2006. Silverleaf whitefly induces salicylic acid defenses and suppresses effectual jasmonic acid defenses. Plant Physiol. 143:866-875. 